\title{
Hemoglobinúria Paroxística Noturna e Gravidez
}

\author{
Paroxysmal Nocturnal Hemoglobinuria in Pregnancy
}

Marcelo Luís Nomura, Fernanda Garanhani De Castro Surita, Mary Angela Parpinelli, Egle Cristina Couto Carvalho, Renato Passini Júnior

\section{RESUMO}

\begin{abstract}
A hemoglobinúria paroxística noturna é doença rara, causada por mutação adquirida de um gene no sistema hematopoético com 16-18\% dos casos diagnosticados durante a gravidez. Descrevemos dois casos de gestantes portadoras de hemoglobinúria paroxística noturna com diagnóstico anterior à gestação. A mortalidade materna é de 8-10\%, devido principalmente a tromboembolismo e, em menor escala, transformação leucêmica. As perdas fetais chegam a $30 \%$ das gestações. Estes dois casos ilustram situação grave e extremamente complexa, que é a conduta obstétrica em mulheres portadoras de doença hematológica muito rara, grave e potencialmente fatal. Com uma abordagem multidisciplinar em serviços terciários é possível obter bons resultados maternos e perinatais.
\end{abstract}

PALAVRAS-CHAVE: Hemoglobinúria. Aplasia medular. Gestação: complicações.

\section{Introdução}

A hemoglobinúria paroxística noturna (HPN) foi uma das primeiras doenças hematológicas descritas a partir de sintoma específico, a saber, a urina escurecida no período noturno. É doença das células-tronco hematopoéticas causada por mutação de um gene ligado ao cromossomo $\mathrm{X}$, que decodifica uma proteína da sintese de um fosfolípide (glicosilfosfatidilinositol - GPI) que ancora algumas proteínas da membrana celular. Há cerca de 15 proteínas defeituosas ou ausentes descritas associadas a HPN, e esta instabilidade da membrana celular é a causa básica das anormalidades das células na HPN, por meio da ativação do sistema complemento. É doença rara, com incidência estimada de 1 a 10 a cada 1 milhão de indivíduos, afetando igualmente homens e mulheres $^{1}$.

Centro de Atenção Integral à Saúde da Mulher Departamento de Tocoginecologia da Faculdade de Ciências Médicas - Universidade Estadual de Campinas

Correspondência:

Marcelo Luís Nomura

Rua Alexander Fleming, 101 - Cidade Universitária Zeferino Vaz

13084-881 - Campinas - SP

Telefone: (19) 3788-9304

Fax: (19) 3788-9304

e-mail: mlnomura@unicamp.br
O diagnóstico é feito, laboratorialmente, pelo teste de Ham, que consiste na detecção de hemólise das células anormais quando o soro é acidificado, ou pela citometria de fluxo, que quantifica o GPI, pela dispersão em feixes de laser causada pela passagem de células em fila dentro de uma coluna de líquido, método este mais sensível, uma vez que utiliza anticorpos monoclonais que detectam a proporção de granulócitos e monócitos que não possuem a proteína CD59, ausente na $\mathrm{HPN}^{2-4}$.

O tratamento, em linhas gerais, consiste na reposição de ferro e ácido fólico, de hemoderivados, uso de prednisona, de hormônios androgênicos (danazol), anticoagulantes e transplante de medula óssea. A ocorrência de trombose, pancitopenia, mielodisplasia ou aplasia medular e leucemia piora o prognóstico de pacientes portadores de HPN, sendo que a sobrevida em dez anos é de $50-60 \%{ }^{4,5}$. A associação com a gravidez é rara, porém a gestação é reconhecida por alguns autores como um fator de recorrência ou de piora dos casos com aplasia medular ${ }^{3,4,6}$.

\section{Descrição do Caso 1}

L.A.S., 27 anos, gesta 2 para 1, com diagnóstico de HPN há 3 anos, após quadro de aplasia de 
medula óssea. Durante a primeira gestação, dois anos após o diagnóstico, também se apresentava em remissão, e não apresentou intercorrências, segundo informações da própria paciente. Iniciou pré-natal com cerca de 20 semanas, em setembro de 1999, com doença em remissão há cerca de sete meses, com hemogramas normais, sem evidências clínicas de sangramento cutâneo-mucoso, tromboses vasculares e hemoglobinúria, e não estava em uso de imunossupressores. Avaliações ecográficas seriadas não evidenciaram sinais de trombose supra-hepática. Não apresentou intercorrências significativas até a 35a a semana, quando apresentou episódio de aplasia de medula óssea, com anemia grave e plaquetopenia intensa (4670 plaquetas $/ \mathrm{mm}^{3}$ ). Não apresentava alterações de função renal ou hepática. Foi submetida a transfusão de concentrado de plaquetas e o trabalho de parto foi induzido com misoprostol. Evoluiu para parto vaginal, sem episiotomia e sem lacerações de canal de parto, com recém-nascido de termo, pesando $3.080 \mathrm{~g}$ e índice de Apgar 9 e 10. Foi realizada coleta de sangue do cordão umbilical para tentativa de transplante de medula óssea. No $6^{\text {o }}$ dia pós-parto apresentou febre e sangramento vaginal, porém sem outros sinais de endometrite. Foi tratada com cefepima e fluconazol, com remissão do quadro febril e controle do sangramento. O transplante de medula a partir das células do cordão umbilical foi contraindicado por incompatibilidade. Atualmente, quatro anos depois do parto, apresenta doença controlada, estando em uso de ciclosporina e óxido de magnésio.

\section{Descrição do Caso 2}

N.R.S.C., 40 anos, gesta 6, com 4 abortamentos espontâneos, apresentava diagnóstico de HPN há dez anos, após sucessivos episódios de hematúria que se seguiam a febre, relatando também hematúria durante as gestações anteriores. Iniciou seguimento pré-natal em maio de 2003, na $8^{\mathrm{a}}$ semana de gestação, assintomática. Pelo antecedente de abortamentos de repetição, foi realizada pesquisa de trombofilias (sindrome antifosfolípide, mutação do fator $\mathrm{V}$ de Leiden, mutação do gene da protrombina) e lúpus eritematoso sistêmico, com resultados negativos. Iniciado ácido acetilsalicílico, $100 \mathrm{mg}$ ao dia, e ácido fólico 5 $\mathrm{mg}$ ao dia. Na $35^{\mathrm{a}}$ semana de gestação apresentou episódio de ameaça de parto prematuro, sendo internada com conduta expectante. Apresentava colonização por Streptococcus agalactiae, com cultu- ras anais e vaginais positivas. Na $37^{a}$ semana foi internada novamente com elevação dos níveis pressóricos e presença de proteína no sedimento urinário, com diagnóstico de pré-eclâmpsia leve. A pressão arterial foi controlada com metildopa e a avaliação laboratorial evidenciava proteinúria de 24 horas de 0,59 g. Os outros exames de função renal (ácido úrico, creatinina e depuração de creatinina) e função hepática estavam dentro dos limites normais. Foi submetida a parto cesariano com 37 semanas e 3 dias de gestação por préeclâmpsia leve, sob anestesia peridural simples, sem intercorrências, dando à luz a recém-nascido de termo, pesando 2.825 g. Não apresentou intercorrências no puerpério. No $45^{\circ}$ dia pós-parto, retornou para consulta de revisão puerperal, assintomática, sendo prescrita medroxiprogesterona trimestral como método anticoncepcional. $\mathrm{O}$ recém-nascido não apresentou alterações clínicas até este período. Atualmente se encontra assintomática, em seguimento hematológico.

\section{Discussão}

O quadro clínico da HPN envolve, além da hemoglobinúria, que é reflexo da hemólise intravascular mediada por complemento, tromboses venosas e deficiências da hematopoiese. Ham, em 1938 (v. Rosse ${ }^{1}$ ), definiu o que viria a ser o principal achado diagnóstico: a hemólise desencadeada por complemento. Posteriormente, foram descritas associações com aplasia medular, que poderia surgir antes do diagnóstico ou no decurso da HPN. Alguns pacientes também podem apresentar leucemia mielóide aguda (1-5\%), que é a causa de óbito em pequena porcentagem dos casos. A hemólise é causada por ativação do complemento, o que ocorre em maior grau na concomitância de infecções virais ou bacterianas, e seu caráter noturno é atribuído à maior absorção do lipopolissacarídeo pelo trato digestivo ${ }^{4}$. Se a hemólise for maciça, pode ocorrer insuficiência renal, que causa 5\% dos óbitos relacionados a HPN a longo prazo. As tromboses venosas ocorrem principalmente nas veias intra-abdominais, podendo levar à sindrome de Budd-Chiari, mas também podem ocorrer no tecido subcutâneo, cérebro e rins ${ }^{1,5}$.

A HPN pode estar associada à gestação e 16-18\% dos casos são diagnosticados durante o ciclo grávido puerperal ${ }^{6}$. A morbidade e a mortalidade materna costumam ser elevadas. Em série recente, do European Group for Blood and Marrow Transplantation Severe Aplastic Anaemia Working Party, constituída por 36 gestantes, seis delas apre- 
sentavam HPN. Em todas as gestações ocorreram complicações. Uma das gestantes apresentou recorrência da anemia aplásica refratária ao tratamento e morreu um ano após o parto. Outra paciente não apresentou intercorrências durante a gravidez, mas dezessete dias após o parto evoluiu com cistite bacteriana e foi a óbito 7 dias após, com trombose cerebral. Uma paciente apresentou crise de aplasia medular e outra, trombocitopenia persistente, necessitando de transfusões freqüentes. Houve um caso complicado por eclâmpsia. Três das seis pacientes necessitaram de transfusões com menor intervalo ${ }^{5}$.

Numa publicação na qual foram incluídas 65 gestações, ocorreram 3 óbitos maternos por hemorragia digestiva ocasionada por varizes de esôfago, complicada por sepse pulmonar e hemorragia intracraniana. Outra gestante foi a óbito por úlcera péptica hemorrágica complicada por sepse e hemorragia intracraniana, e outro óbito foi causado por sepse secundária a um abscesso glúteo e colite amebiana. Excluindo as interrupções voluntárias da gestação (oito casos), ocorreram vinte perdas gestacionais, dez no primeiro trimestre e dez no segundo trimestre. As complicações hemorrágicas e infecciosas estão relacionadas, principalmente, à supressão medular ${ }^{7}$.

Em revisão de 33 gestações em portadoras de HPN, a incidência de tromboembolismo foi de $12,1 \%$, com dois casos ocorrendo durante a gestação e dois no puerpério; três destas pacientes evoluíram para óbito. Anemia e trombocitopenia foram extremamente freqüentes $(72,7$ e $27,3 \%$, respectivamente). A taxa de prematuridade foi de $54,8 \%$ e a taxa de mortalidade perinatal foi de $8,8 \%$ (3 em 34 nascimentos) ${ }^{8}$. O índice de perdas gestacionais (abortamentos e óbitos fetais e neonatais) é elevado em todas as séries encontradas.

Numa revisão mais ampla com 86 gestações em 60 pacientes portadoras de HPN, a mortalidade materna foi de 5,8\% (cinco mulheres, três delas por complicações da síndrome de Budd-Chiari e duas por infecções). Crises hemolíticas ocorreram em 28\% das mulheres, $14 \%$ apresentaram tromboembolismo e $14 \%$ apresentaram quadros hemorrágicos, principalmente cerebrais. $\mathrm{O}$ indice de perdas gestacionais foi de 30\%. A taxa de prematuridade foi de $17 \%$ entre os nascidos vivos. A síndrome de Budd-Chiari é responsável por cerca de $50 \%$ dos óbitos maternos ${ }^{6}$.

As gestantes portadoras de HPN em remissão têm prognóstico melhor, porém, como no caso descrito neste artigo, as recorrências podem ser bastante graves, especialmente as aplasias medulares. A manutenção de níveis adequados de hemoglobina materna e fetal demanda elevada freqüência transfusional, com os riscos associados. É necessária a reposição oral de ácido fólico e ferro. O uso de corticóides pode ser benéfico para algumas gestantes, reduzindo os eventos hemorrágicos ${ }^{4}$. A terapia hormonal é, obviamente, contra-indicada durante a gestação. A profilaxia de fenômenos tromboembólicos é obrigatória para todas as mulheres com este antecedente, com heparina não fracionada ou de baixo peso molecular. No entanto, a HPN é estado hipercoagulável, com um risco elevado de tromboembolismo, e alguns autores recomendam anticoagulação profilática para todas as gestantes portadoras, mesmo sem antecedentes de tromboembolismo ${ }^{8}$. O transplante de medula óssea é o tratamento definitivo, podendo-se utilizar células totipotencias fetais extraídas do cordão umbilical.

Outro aspecto importante na assistência a estas gestantes se refere ao trabalho de parto e à via de parto. A analgesia de parto se torna complicada em situações de coagulopatia, quando o risco de hematomas epidurais é grande. No entanto, há relato de caso de analgesia epidural com cateter em gestante portadora de HPN e trombocitopenia $^{3}$. O índice de cesarianas está diretamente relacionado à atividade da doença, sendo que taxas de até $86 \%$ são relatadas em mulheres com aplasia medular6. A administração de plaquetas é necessária para as pacientes com niveis de risco de sangramento (contagem de plaquetas menor que 50 mil por $\mathrm{mm}^{3}$ ), independente da via de parto; no entanto, o parto vaginal acarreta menor risco de hemorragia que a cesariana. Infecções também são mais freqüentes, especialmente em pacientes leucopênicas, e deve ser dada atenção especial à profilaxia antibiótica, utilizando esquemas alargados e de amplo espectro. A bacteriúria assintomática também deve ser rastreada. A aceleração de maturidade pulmonar fetal pode ser considerada, e não está contra-indicada pela doença. O rastreamento ecográfico de trombose das veias supra-hepáticas deve ser realizado durante a gestação, para que a anticoagulação possa ser instituída a tempo de prevenir a evolução para hipertensão portal e suas conseqüências ${ }^{4}$.

Não há dúvida de que gravidez e HPN é associação de alto risco, além de ser muito rara. Até o momento, foram descritos menos de 100 casos diagnosticados durante a gravide $z^{9}$. O seguimento em hospitais terciários é obrigatório, com equipes multidisciplinares, incluindo obstetra, hematologista, intensivista e anestesiologista. A gestação deve ser desaconselhada em mulheres ainda não submetidas ao transplante de medula óssea e que sejam portadoras de aplasia de medula ou de seqüelas de tromboembolismo, como a síndrome de 
Budd-Chiari. O prognóstico, mesmo em gestantes em remissão, é imprevisivel, e uma gravidez prévia sem intercorrências não é garantia de futuras gestações não complicadas, como demonstrado neste relato. É possível que tendência a publicações de casos mais graves exista, mas, ainda assim, aparentemente, há redução na expectativa de vida destas mulheres ${ }^{10}$. É importante que obstetras e hematologistas atuem em conjunto, garantindo anticoncepção adequada e discutindo individualmente com estas mulheres a indicação de esterilização definitiva nos casos mais graves.

\section{ABSTRACT}

Paroxysmal nocturnal hemoglobinuria is a rare disease caused by an acquired gene mutation of the hematopoietic system, with 16-18\% of the cases diagnosed during pregnancy. We describe two cases of pregnancy in women with paroxysmal nocturnal hemoglobinuria. Maternal mortality reaches $8-10 \%$, mainly due to thromboembolism and, less frequently, to leukemic transformation. Fetal losses may reach $30 \%$. These two cases illustrate a serious and extremely complex situation, which is the obstetrical management of a patient with a very rare, serious and potentially fatal hematological condition. Using a multidisciplinary approach in tertiary care centers, it is possible to attain good maternal and perinatal outcomes.

KEYWORDS: Hemoglobinuria. Medullary aplasia. Pregnancy complications.

\section{Referências}

1. Rosse WF. Paroxysmal nocturnal hemoglobinuria as a molecular disease. Medicine (Baltimore) 1997; 76:63-93.
2. Stocche RM, Garcia LV, Klamt JG. Labor analgesia in a patient with paroxysmal nocturnal hemoglobinuria with thrombocytopenia. Reg Anesth Pain Med 2001; 26:79-82.

3. Ball SE. The modern management of severe aplastic anemia. Br J Haematol 2000; 110:41-53.

4. Parker CJ, Ware RE. Paroxysmal nocturnal hemoglobinuria. In: Greer JP, Foerster J, Lukens JM, Rodgers GM, Paraskevas F, Glader B, editors. Winthrobe's Clinical Hematology. $11^{\text {th }}$ ed. Philadelphia: Lippincott, Williams \& Wilkins; 2004 [cited 2004 Apr 5]. Available from: http://pco.ovid.com/ lrppco/index.html

5. Bais J, Pel M, von dem Borne A, van der Lelie $H$. Pregnancy and paroxysmal nocturnal hemoglobinuria. Eur J Obstet Gynecol Reprod Biol 1994; 53:211-4.

6. Tichelli A, Socie G, Marsh J, et al. Outcome of pregnancy and disease course among women with aplastic anemia treated with immunosupression. Ann Intern Med 2002; 137:164-72.

7. Svigos JM, Norman J. Paroxysmal nocturnal haemoglobinuria and pregnancy. Aust N Z J Obstet Gynaecol 1994; 34:104-6.

8. Ray JG, Burrows RF, Ginsberg JS, Burrows EA. Paroxysmal nocturnal hemoglobinuria and the risk of venous thrombosis: review and recommendations for management of the pregnant and nonpregnant patient. Haemostasis 2000; 30:103-17.

9. Bjorge L, Ernst P, Haram KO. Paroxysmal nocturnal hemoglobinuria in pregnancy. Acta Obstet Gynecol Scand 2003; 82:1067-71.

10.Bais JM, Pel M. Late maternal mortality due to paroxysmal nocturnal hemoglobinuria and pregnancy. Eur J Obstet Gynecol Reprod Biol 1995; $58: 211$. 